\title{
Are ORCs a Good Option for Waste Heat Recovery in a Petroleum Refinery?
}

\author{
B. M. Mazetto ${ }^{1}$, J. A. M. Silva ${ }^{2 *}$, S. Oliveira Jr. ${ }^{3}$ \\ ${ }^{1}$ Mechanical Engineering Department, Polytechnic School, University of São Paulo, São Paulo, Brazil \\ ${ }^{2}$ Mechanical Engineering Department, Polytechnic School, Federal University of Bahia, Salvador, Brazil \\ ${ }^{3}$ Mechanical Engineering Department, Polytechnic School, University of São Paulo, São Paulo, Brazil \\ E-mail: 'bmazetto@gmail.com, ${ }^{2}$ julio.silva@ufba.br, ${ }^{3}$ soj@usp.br
}

Received 30 September 2014, Revised 26 November 2014, Revised 27 March 2015, Accepted 19 June 2015

\begin{abstract}
The studies regarding Organic Rankine Cycles (ORCs) have been intensified due to the capacity of these systems to convert low-grade energy sources such as geothermal, solar and industrial waste heat into electricity. In this work optimized configurations of ORCs are compared with conventional options of industrial waste heat recovery such as preheating of boiler feed water and cooling of the gas turbine inlet air using an absorption chiller. The study was focused on the recovery of thermal exergy of a diesel stream in a typical petroleum refinery. Several organic working fluids were tested. The cycle parameters were optimized for each working fluid using two different objective functions: to maximize net power output and to maximize the power to heat transfer area ratio. R134a was the organic fluid that generated maximum power output $(\sim 940 \mathrm{~kW})$ while water was the fluid that generated maximum power to area ratio $(\sim 650 \mathrm{~W} / \mathrm{m} 2)$. The comparison of these optimized configurations with other alternatives of heat recovery shows that the gas turbine inlet air cooling coupled with boiler feed water preheating is the best option to increase overall net power output and efficiency. The ORCs were the last option for the analyzed conditions.
\end{abstract}

Keywords: ORC; refinery; heat recover; processes integration; power generation.

\section{Introduction}

Over the last years, the society has expressed an increasing concern over emissions of greenhouse gases, mainly $\mathrm{CO}_{2}$ from fossil fuel combustion. In response to this fact, governments and companies all over the world have been adopting sustainable policies to reduce fossil fuels consumption, to improve processes efficiencies and to expand renewable energy sources participation in the world energy matrix. The Organic Rankine Cycles (ORC) are known since later years of XIX. However, in recent years ORCs got the attention of industry for their capacity to make use of residual and low-grade energy with reasonable efficiencies (exergy efficiencies). Several characteristics make ORC more suitable than water Rankine cycle for lowgrade energy applications: reasonable boiling pressures at low temperatures and reasonable condensation pressures near environment temperatures so that proper pressure difference in turbine can be obtained. In most scenarios, the condensation pressure in ORCs avoids the use of vacuum in the condenser (ejectors, vacuum pumps and deaerator can be avoided). Some organic fluids have positive or isentropic slopes for saturation line. It avoids humidity in the later stages of turbine expansion improving turbine efficiency and its operational life.

Several low-grade energy sources are available: solar energy, geothermal energy, biomass products, surface seawater, and waste heat from various thermal processes [1]. As there is no general rule in choosing the best organic fluid and cycle parameters (pressures and temperatures), each application requires its own optimization study. A great number of works are dealing with the determination of the best parameters and organic fluids for a given application [2-
11]. Different objective functions also provide different results: He et al. [6] and Becquin \& Freund [12] chose to optimize the parameters in the direction of designing cycles that provided the greatest net power output.

Papadopoulos et al. [13] used a computational code called CAMD (Computer Aided Molecular Design) so that new working fluid compositions could be obtained. Their work intended to minimize the heat transfer surfaces since they considered that heat exchangers represent most of the investment costs [13]. Wang et al. [8] used a similar criterion in their optimization. Kuo, Hsu, Chang \& Wang [14] defined a "figure of merit" correlated with thermal efficiency and dependent on Jacob number as well as condensing and evaporation temperatures as the evaluation criterion, obtaining R123 as the fittest organic compound. Roy, Mishra \& Misra [15] performed the optimization of turbine inlet pressure in order to maximize work output and thermal and exergy efficiencies, discovering that R123 gives the best results. While most authors focus upon a single objective function, Pierobon et al. [16] employed three objective functions: thermal efficiency, total volume of the system and net present value, which showed that cyclopentane would produce the greatest outcome. Some other authors studied modification and new options of cycle configuration to make use of low-grade heat, such as Becquin \& Freund [12] and Li et al. [17]. Kang [18] performed an experimental study using radial turbine in ORC.

Jung et al [19] evaluated one of the several opportunities to generate electricity from waste heat in a refinery. An ORC is used to cool down a pump around stream (kerosene range) in a vacuum distillation tower. For an investment cost of $\$ 3.000 / \mathrm{kW}$ the study shows a reasonable internal rate of 
return $(21.8 \%)$ and payback period (6.8 years). In the present work the ORC uses heat from a refinery diesel stream as heat source. This stream is cooled down prior storage, in order to avoid high fuel vapor pressures, consuming power and water for its cooling. Cycle parameters are optimized for each organic fluid tested. Unlike many studies in the literature that simply assume saturated vapor at turbine inlet, the ORC optimization is here carried out using two independent variables (turbine inlet pressure and turbine inlet temperature). Moreover, the effects of two different objective functions are evaluated. The organic fluids that provided the largest power output and largest power to area ratio are compared with other options of heat recovery: absorption chiller to increase the power output of a gas turbine and heat integration to increase the boiler feed water temperature. These options are usually available in refinery utilities plants. In order to make the comparisons reasonable, the total heat transfer area for the optimized ORC was calculated and used as input for the other alternatives evaluated.

\section{System Modeling}

\subsection{System Description}

The configuration of the ORC for waste heat recovery as well as the cycle representation on a $T-s$ diagram are shown in Figure 1. The system consists of a working fluid pump, five heat exchangers, an expander and a generator. Since only sub-critical ORCs are investigated in this study, saturated liquid at the outlet of the condenser (state 1) is compressed by the pump to pressures below the critical one. After being pressurized (state 2), the working fluid is heated to saturated temperature in the economizer (state 3) and turned into saturated vapor in the evaporator (state 4). Next, this vapor has its temperature raised in the superheater (state 5). Depending on the cycle configuration and type of working fluid, the superheating process might be unnecessary, therefore the expander would receive vapor directly from the evaporator. Independently of the state of the vapor, in both Scenarios the working fluid is expanded to the condensing pressure (state 6). Then, if the working fluid at the outlet of the expander is superheated, a cooler is required to lower the vapor temperature to the saturation condition at the entrance of the condenser (state 7); otherwise it is conducted directly to the condenser. After being cooled to the saturation point in the condenser, the working fluid is directed to pump (state 1), reinitiating the cycle processes. Regarding the heat exchangers, it is considered that the condenser and the cooler are water cooled while the economizer, evaporator and superheater are driven by lowgrade waste heat, provided by the cooling of a light diesel stream initially at $140^{\circ} \mathrm{C}$. This stream is produced during the combined distillation process in an oil refinery where it is currently cooled to a temperature around $55^{\circ} \mathrm{C}$ before being stored in diesel pool. The diesel final temperature does not represent a constraint since the diesel stream can still be cooled by refinery cooling tower circuit.

\subsection{Thermodynamic Model}

For the system simulation, it was assumed that the cycle operates under steady-state conditions, pipe pressure drop is ignored, and heat losses to or from the surroundings together with potential and kinetic energy changes are neglected. Furthermore, ORC specifications are given in Table 1.
Table 1. ORC Specifications for Simulation.

\begin{tabular}{lll}
\hline Parameter & Valu & Unit \\
& $\mathrm{e}$ & \\
\hline Light diesel inlet temperature (state & 140 & ${ }^{\circ} \mathrm{C}$ \\
8) & & \\
Light diesel mass flow rate & 66.2 & $\mathrm{~kg} / \mathrm{s}$ \\
Light diesel average specific heat & 2.11 & $\mathrm{~kJ} / \mathrm{kg} \mathrm{K}$ \\
Environment pressure & 100 & $\mathrm{kPa}$ \\
Environment temperature & 25 & ${ }^{\circ} \mathrm{C}$ \\
Cooling water temperature & 25 & ${ }^{\circ} \mathrm{C}$ \\
Working fluid condensing & 45 & ${ }^{\circ} \mathrm{C}$ \\
temperature & & \\
Pinch temperature difference in & 10 & ${ }^{\circ} \mathrm{C}$ \\
evaporator & & \\
Pinch temperature difference in & 10 & ${ }^{\circ} \mathrm{C}$ \\
condenser & & \\
Expander Isentropic efficiency & $80 \%$ & - \\
Pump Isentropic efficiency & $75 \%$ & - \\
Generator efficiency & $96 \%$ & - \\
Total physical exergy of light diesel & 2479 & $\mathrm{~kW}$ \\
\hline
\end{tabular}

The energy balance and efficiency equations applied to the equipment shown in Figure 1 are given by the following equations. Power consumed by the pump and pump isentropic efficiency are given in Eqs. (1) and (2) in which the subscript "wf" stands for working fluid.

$W_{P}=m_{w f} \cdot\left(h_{1}-h_{2}\right)$

$\eta_{p, \text { ise }}=\frac{\left(h_{1}-h_{2, \text { ise }}\right)}{\left(h_{1}-h_{2}\right)}$

Economizer, evaporator and superheater energy balances are given in Eqs. (3), (4) and (5) in which the subscript "LD" stands for light diesel and "avg" for average value. Heat transferred to the working fluid is given by " $\mathrm{QH}$ " in Eq. (6).

$$
\begin{aligned}
& m_{w f} \cdot\left(h_{3}-h_{2}\right)=m_{L D} \cdot C_{L D, a v g} \cdot\left(T_{10}-T_{11}\right) \\
& m_{w f} \cdot\left(h_{4}-h_{3}\right)=m_{L D} \cdot C_{L D, a v g} \cdot\left(T_{9}-T_{10}\right) \\
& m_{w f} \cdot\left(h_{5}-h_{4}\right)=m_{L D} \cdot C_{L D, a v g} \cdot\left(T_{8}-T_{9}\right) \\
& Q_{H}=m_{L D} \cdot \mathrm{C}_{L D, a v g} \cdot\left(T_{8}-T_{11}\right)
\end{aligned}
$$

Expander and generator equations are given in Eqs. (7), (8) and (9) in which " $T$ " stands for turbine and "ger" for generator.

$W_{\mathrm{T}}=m_{\mathrm{wf}} \cdot\left(h_{5}-h_{6}\right)$

$\eta_{T, \text { ise }}=\frac{\left(h_{5}-h_{6}\right)}{\left(h_{5}-h_{6, i s e}\right)}$ 

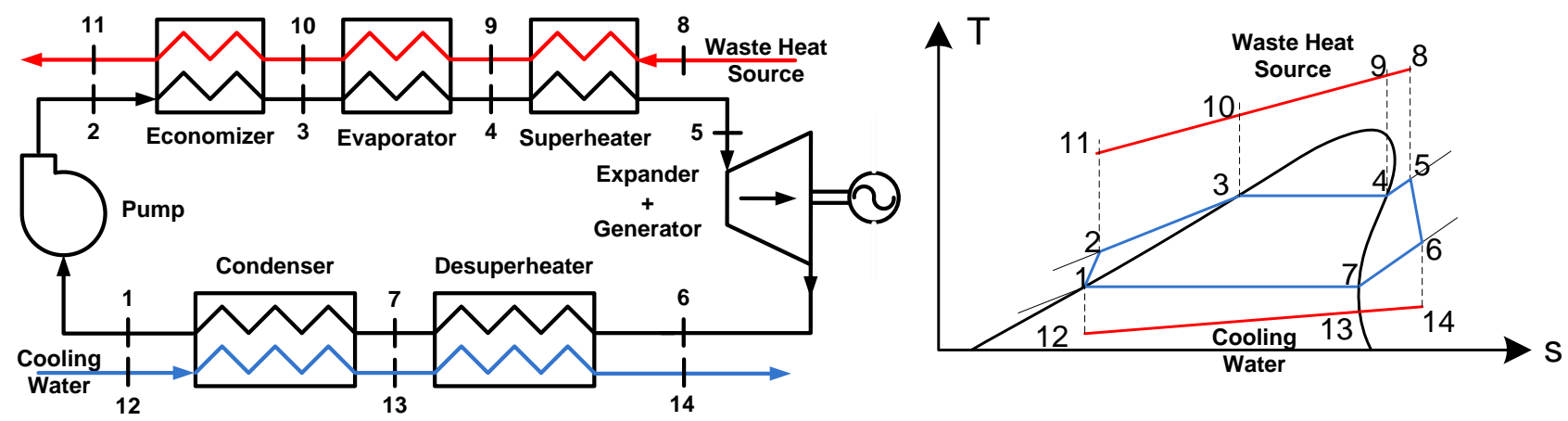

Figure 1. (a)Schematic diagram of the ORC; (b) T-s diagram.

$$
\mathrm{W}_{\mathrm{ger}}=\eta_{\mathrm{ger}} \cdot \mathrm{W}_{\mathrm{T}}
$$

Desuperheater and condenser equations are given in Eqs. (10) and (11) in which "c" stands for cooling water.

$$
\begin{aligned}
& m_{\mathrm{wf}} \cdot\left(h_{7}-h_{6}\right)=m_{c} \cdot\left(h_{13}-h_{14}\right) \\
& m_{\mathrm{wf}} \cdot\left(h_{1}-h_{7}\right)=m_{c} \cdot\left(h_{12}-h_{13}\right)
\end{aligned}
$$

Thus, cycle net power, thermal and exergy efficiency are shown in Eqs. (12), (13) and (14) in which "thm" stands for thermal and "exg" for exergy.

$$
\begin{aligned}
& \mathrm{W}_{\text {net }}=\mathrm{W}_{\text {ger }}-\mathrm{W}_{\mathrm{p}} \\
& \eta_{\text {thm }}=\frac{\mathrm{W}_{\text {net }}}{\mathrm{Q}_{\mathrm{H}}} \\
& \eta_{\text {exg }}=\frac{\mathrm{B}_{\text {power }}}{\mathrm{B}_{\text {in }}}=\frac{\mathrm{W}_{\text {net }}}{\mathrm{m}_{\mathrm{LD}} \cdot \mathrm{C}_{\mathrm{LD}, \text { avg }} \times\left(\left(\mathrm{T}_{8}-\mathrm{T}_{11}\right)-\mathrm{T}_{0} \times \ln \left(\frac{\mathrm{T}_{8}}{\mathrm{~T}_{11}}\right)\right)}
\end{aligned}
$$

In Eq. (14), it is assumed that the light diesel, which is liquid at the temperatures considered, is incompressible and $\mathrm{T}_{0}$ is the environment temperature $\left(25^{\circ} \mathrm{C}\right)$. As $T_{11}$ is free to vary, different values for $B_{\text {in }}$ and $\mathrm{Q}_{\mathrm{H}}$ can be found. Since heat exchangers account for largest part of ORC total cost, as mentioned by Li et al. [11], Papadopoulos et al. [13], Quoilin et al. [20] and Wang et al. [21], the method applied to estimate the economic performance of the ORC cycle considers the ratio of total net power to total heat transfer area (PTA), as given in Eq. (15).

$$
\mathrm{PTA}=\frac{\mathrm{W}_{\text {net }}}{\mathrm{A}_{\text {Total }}}=\frac{\mathrm{W}_{\text {net }}}{\mathrm{A}_{\mathrm{ECO}}+\mathrm{A}_{\mathrm{EVA}}+\mathrm{A}_{\mathrm{SUP}}+\mathrm{A}_{\mathrm{DES}}+\mathrm{A}_{\mathrm{CON}}}
$$

\subsection{Heat Transfer Area}

All heat transfer devices of the studied ORC system were considered to be shell-and-tube heat exchangers, since this type of equipment provides relatively large ratios of heat transfer to volume and weight and presents reliable design procedures [22]. Moreover, it was defined that the working fluid runs through the interior of the tubes in any of the heat exchangers and this flow is fully developed. This way, the hot fluid - light diesel - in the economizer, evaporator and superheater as well as the cold fluid - cooling water - in the condenser and cooler flow into the shell through a distribution system and move uniformly over tubes. Besides, these streams are in counter current, and a single shell and a single tube pass was considered.

In order to calculate the area required for each heat exchanger, numerical correlations are employed to calculate the Nusselt number and convective coefficients for both hot fluid and cold fluid, which leads to the overall heat transfer coefficient. Furthermore, thermodynamic properties of working fluids needed for correlations were obtained from EES [23] and the temperature differences were obtained from the cycle design. Fouling effects were also considered, and the resistances associated with them are presented in

\begin{tabular}{|c|c|c|c|}
\hline Component & $\begin{array}{l}\text { Shell- } \\
\text { Side }\end{array}$ & Tube-Side & $\mathrm{U}_{\text {overall }}\left(\mathrm{W} / \mathrm{m}^{2} \mathrm{~K}\right)$ \\
\hline Economizer & \multirow{5}{*}{$\begin{array}{l}\text { Bell- } \\
\text { Delaware } \\
\text { Method } \\
{[22]}\end{array}$} & $\begin{array}{l}\text { Webb } \\
\text { Correlation } \\
{[22]}\end{array}$ & $200-800$ \\
\hline Evaporator & & $\begin{array}{l}\text { Shah } \\
\text { Correlations } \\
\text { [23] }\end{array}$ & $640-680$ \\
\hline $\begin{array}{l}\text { Superheater } \\
\text { Coolerr }\end{array}$ & & $\begin{array}{l}\text { Sleicher \& } \\
\text { Rose }\end{array}$ & $100-330$ \\
\hline & & $\begin{array}{l}\text { Correlation } \\
{[22]}\end{array}$ & $100-300$ \\
\hline Condenser & & $\begin{array}{l}\text { Dobson \& } \\
\text { Chato } \\
\text { Correlations } \\
\text { [23] }\end{array}$ & $550-775$ \\
\hline
\end{tabular}
Table 2. The correlations applied for each of the heat exchangers together with the range of overall heat transfer coefficient calculated are indicated in Table 3.

Table 2. Total Fouling Resistance [22].

\begin{tabular}{ll}
\hline Fluid & Resistance $\left(\mathrm{m}^{2} . \mathrm{K} / \mathrm{W}\right)$ \\
\hline Light diesel & 0.00042 \\
Refrigerant liquids and Water & 0.000176 \\
Refrigerant Vapors & 0.000352 \\
\hline
\end{tabular}

Table 3. Heat Transfer Correlations.

\section{Methodology for Optimization of the ORC}

The aim of the simulations is to find, among the working fluid candidates, the one that provides the best result to the selected objective function. In this study, two scenarios are considered to evaluate the ORC performance using EES software, for each an objective function is defined. In Scenario 1, the goal is to maximize the net power output, Eq. (12), in order to make full use of the low-grade waste heat and raise the global efficiency (cycle or process that rejects heat together with the ORC). In Scenario 2, instead of the net power output, the ratio of total net power to total heat transfer area, Eq. (15), is chosen to be maximized, since this 
parameter allows a simultaneous evaluation of the overall capital cost of the ORC system and its useful effect.

To the purpose of maximizing the objective functions, the effects of independent variables on the ORC performance are examined: turbine inlet pressure $\left(\mathrm{P}_{5}\right)$ and temperature $\left(T_{5}\right)$. These parameters were defined by the employment of the genetic algorithm (GA). The genetic algorithm is based on Charles Darwin's theory of evolution and designed to reliably locate a global optimum even in the presence of local optima. The working principle is the following: initially, a population of individuals (possible solutions) is randomly chosen and the adaptability - objective function value - of each one is determined; after that, a new generation is obtained from the current population, whose fittest individuals are prone to pass on their characteristics to descendants. In addition to the selection of the fittest, mechanisms of crossover and mutation also guarantee the characteristics variability of descendants. The adaptability of the new generation is surveyed and the process of reproduction continues. As a result, after a specified number of generations, the individual with the best adaptability is the solution to the optimization problem [23].

Table 4. Working Fluid Candidates.

\begin{tabular}{llll}
\hline Number & Substance & Type & $T_{\text {crit }}\left({ }^{\circ} \mathrm{C}\right)$ \\
\hline 1 & Benzene & Dry & 288.9 \\
2 & Isobutane & Dry & 134.7 \\
3 & n-Butane & Dry & 152.0 \\
4 & n-Decane & Dry & 344.6 \\
5 & n-Dodecane & Dry & 385.0 \\
6 & n-Heptane & Dry & 267.0 \\
7 & n-Hexane & Dry & 234.7 \\
8 & n-Nonane & Dry & 321.4 \\
9 & n-Octane & Dry & 296.2 \\
10 & n-Pentane & Dry & 196.5 \\
11 & Isopentane & Dry & 187.2 \\
12 & Cyclohexane & Isentropic & 280.5 \\
13 & Toluene & Isentropic & 318.6 \\
14 & R123 & Isentropic & 183.7 \\
15 & R134a & Isentropic & 101.0 \\
16 & R141b & Isentropic & 204.2 \\
17 & R142b & Isentropic & 137.1 \\
18 & R245fa & Isentropic & 154.0 \\
19 & R502 & Wet & 82.16 \\
20 & R717 & Wet & 132.3 \\
21 & Ethanol & Wet & 240.8 \\
22 & Propane & Wet & 96.68 \\
23 & Water & Wet & 374.0 \\
\hline
\end{tabular}

\section{Waste Heat Recovery Alternatives}

In order to compare the ORC performance with other waste heat recovery alternatives, the refinery power plant is described in Figure 2. The synthesis plant, base Scenario, has a power output of $55.54 \mathrm{MW}$. The objective of the alternatives is to employ the available low-grade heat to improve the overall plant performance (combined cycle plus the alternative), allowing the comparative evaluation. The options considered are: 1) utilization of an ORC system in parallel with the combined cycle plant; 2) to use a heat exchanger to preheat the condensate of the Rankine cycle; 3 ) using a hot-water driven absorption chiller to cool the air at the inlet of the gas turbine; 4) applying the low-grade heat both to produce hot water for the chiller and to preheat water for the Rankine cycle. To compare the analyzed alternatives, the sum of the heat transfer area of all heat exchangers for each option must not be superior to the total area obtained for the ORC system with best performance. This restriction yields similar equipment costs to the waste heat recovery alternatives. Concerning the equipment, the combined cycle has a RB211 gas turbine, whose operation curve was obtained from Silva et al. [24]. Besides, two models of chillers described in THERMAX Hot Water Chillers Specification Sheet [25] were selected to match the available low-grade heat and the heat exchangers area restriction. Both of them have a COP $=0.7$, although different area and cooling capacities are required. The comparative analysis between the four configurations considers two indicators: the overall net power output provided by the power plant together with its modifications; and the thermal efficiency, defined as the ratio of the overall net power output to the heat transferred to the plant due to the combustion of natural gas.

\section{Results}

\subsection{Scenario 1: Maximum Net Power Output}

In Scenario 1 the ORC parameters were optimized for each working fluid candidate, using genetic algorithm, in order to obtain the highest net power output. Optimal pressure $\left(P_{5}\right)$ and temperature $\left(T_{5}\right)$ at the inlet of the expander are shown in Table 5, along with working fluid mass flow rate $\left(m_{\mathrm{wf}}\right)$, degrees of superheat $\left(\Delta \mathbf{T}_{\text {sup }}\right)$ of the vapor at the expander inlet and outlet light diesel temperature $\left(T_{11}\right)$.

Table 5. Selected Properties for Optimal Cycle (Scenario 1)

\begin{tabular}{lllllll}
\hline No. & Substance & $\begin{array}{l}m_{\mathrm{wf}} \\
(\mathrm{kg} / \mathrm{s})\end{array}$ & $\begin{array}{l}P_{5} \\
(\mathrm{kPa})\end{array}$ & $\begin{array}{l}T_{5} \\
\left({ }^{\circ} \mathrm{C}\right)\end{array}$ & $\begin{array}{l}\Delta T_{\text {sup }} \\
\left({ }^{\circ} \mathrm{C}\right)\end{array}$ & $\begin{array}{l}T_{11} \\
\left({ }^{\circ} \mathrm{C}\right)\end{array}$ \\
\hline 1 & Benzene & 16.2 & 110.8 & 92.4 & 9.4 & 84.9 \\
2 & Isobutane & 23.0 & 1723.0 & 92.6 & 0 & 81.1 \\
3 & n-Butane & 20.0 & 1264.0 & 90.5 & 0 & 83.0 \\
4 & n-Decane & 17.8 & 6.0 & 88.4 & 0 & 85.4 \\
5 & n-Dodecane & 18.0 & 1.1 & 87.2 & 0 & 85.1 \\
6 & n-Heptane & 16.7 & 82.4 & 91.5 & 0 & 88.1 \\
7 & n-Hexane & 17.4 & 188.3 & 90.8 & 0 & 87.1 \\
8 & n-Nonane & 17.5 & 14.0 & 89.0 & 0 & 85.9 \\
9 & n-Octane & 17.4 & 32.9 & 89.4 & 0 & 86.3 \\
10 & n-Pentane & 17.4 & 489.1 & 91.8 & 0 & 87.0 \\
11 & Isopentane & 17.4 & 648.1 & 95.1 & 0 & 89.4 \\
12 & Cyclohexane & 17.2 & 120.3 & 86.6 & 0 & 86.0 \\
13 & Toluene & 16.3 & 47.9 & 86.0 & 0 & 87.2 \\
14 & R123 & 40.8 & 609.6 & 88.9 & 0 & 84.9 \\
15 & R134a & 70.0 & 4037.0 & 106.6 & 5.8 & 55.2 \\
16 & R141b & 31.4 & 498.4 & 86.8 & 0 & 84.9 \\
17 & R142b & 39.1 & 1691.0 & 89.4 & 0 & 81.6 \\
18 & R245fa & 40.2 & 963.6 & 88.1 & 0 & 80.5 \\
19 & R502 & 68.4 & 3839.0 & 120.7 & 41.5 & 64.3 \\
20 & R717 & 6.0 & 4726.0 & 129.4 & 43.2 & 87.0 \\
21 & Ethanol & 6.6 & 141.6 & 123.1 & 36.1 & 91.2 \\
22 & Propane & 34.7 & 4218.0 & 107.0 & 10.7 & 55.1 \\
23 & Water & 2.4 & 67.6 & 126.8 & 37.8 & 95.8 \\
\hline
\end{tabular}




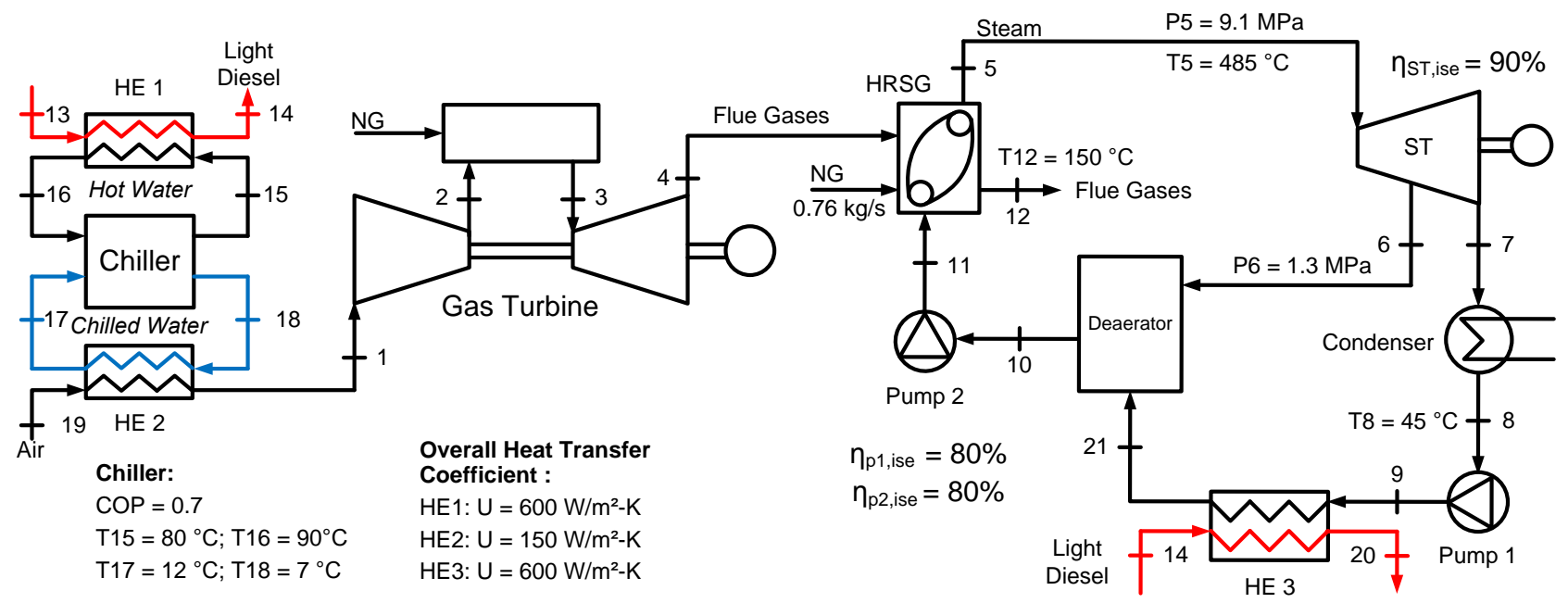

Figure 2. Combined cycle with an absorption Chiller and condensate preheating (NG: Natural Gas).

Pressure and temperature vary significantly according to the chosen working fluid. The upper pressure of the cycle may be inferior to the atmospheric pressure or even higher than $4 \mathrm{MPa}$. As the temperature is limited by the heat source, it stays between 85 and $130^{\circ} \mathrm{C}$. Besides, the optimal cycle may require the superheating of vapor. Regarding mass flow rate, the range is also wide, from $2.4 \mathrm{~kg} / \mathrm{s}$ for water to 70.0 $\mathrm{kg} / \mathrm{s}$ for R134. Thus, the design and cost of the ORC greatly depend on the selected working fluid.

\subsubsection{ORC Simulation and Optimization}

Figure 3 shows the maximum net power output obtained for each working fluid. Among the working fluids considered, it is shown that the most suitable would be $\mathrm{R} 134 \mathrm{a}$ (isentropic), propane (wet) and isobutane (dry), which would produce approximately $940 \mathrm{~kW}, 900 \mathrm{~kW}$ and $650 \mathrm{~kW}$ of net power output, respectively. On the other hand, using R502 and water, both wet fluids, represents the worst scenario, since their power production of $500 \mathrm{~kW}$ and 560 $\mathrm{kW}$ were the lowest obtained. Regarding thermal efficiency, the values are between $5 \%$ and $9 \%$. Water is the most efficient while R502 is the least. It is worth noting that water has a low net power output while has high thermal efficiency. It happens since a low quantity of heat is transferred while its conversion into power takes place efficiently. Considering the exergy efficiency, the values vary from $23 \%$ to $41 \%$. It is worth noting that exergy efficiency takes the low quality of waste heat (low temperature) into consideration. Thus, the exergy efficiency of the ORCs is higher than energy efficiency, reaching values equal to those found for regular Rankine cycles. Although average energy efficiency is found for R134a its exergy efficiency is high since lower grade energy (lower value for $\mathrm{T}_{11}$ ) is converted into power. It also explains its high net power output value.

In Figure 4, the main goal is to compare the total amount of heat exchanger surface and the power-to-area ratio of the working fluids candidates optimized for maximum net power. The fluids propane, R134a and R502 require the largest amount of total heat transfer area to provide the net power output presented in Figure 3. Therefore, a greater investment would be necessary, which could make other fluids for ORC or even other waste heat recovery alternatives more interesting from an economical point of view. This situation reflects $\mathrm{R} 134 \mathrm{a}$ and propane low PTA. It is important to highlight that the lowest total surface and the highest PTA were found for water.

\subsubsection{Waste Heat Recovery Alternatives}

In order to compare the best ORC for net power output (R134a; $\sim 940 \mathrm{~kW}$ ) with other alternatives, the total area $\left(3,484 \mathrm{~m}^{2}\right)$ required for heat transfer in the ORC was used as input for the other alternative systems. Table 6 shows that the combined cycle plant - CCP (refinery utilities plant), Figure 2, using a heat exchanger area of 3,484 $\mathrm{m}^{2}$ to preheat the HRSG feed water would provide approximately $58 \mathrm{MWe}$ while the composition CCP+ORC would provide only 56.5 MW. If the waste heat were used to produce hot water for an absorption chiller to cool the CCP gas turbine inlet air, only $2.237 \mathrm{~m}^{2}$ would be required. This option would produce a net power output for the CCP of approximately $60.5 \mathrm{MWe}$ since the mass flow through the gas turbine would be increased due to the higher density of cooled air. On the other hand the alternatives using chillers have higher natural gas consumption since more energy is necessary to keep the gas turbine inlet temperature constant. A much larger power output is obtained, though. Using the remaining area to preheat the HRSG feed water, the CCP net power output would be increased to values close to $62.5 \mathrm{MWe}$. The highest efficiency is also found for the latter option since the efficiency of gas turbine increases as inlet air temperature decreases and water preheating increases the average temperature in which heat is supplied to the cycle, thus overall efficiency ${ }^{1}$.

\subsection{Scenario 2: Maximum PTA Ratio}

In Scenario 2 the ORC parameters were optimized for each working fluid candidate, using genetic algorithm, Figure 5 and Figure 6, in order to obtain the highest PTA ratio. Table 7 presents the optimal pressure and temperature at the expander inlet, as well as superheating, working fluid mass flow rate and outlet light diesel temperature.
${ }^{1}$ It was considered the efficiency of HRSG constant in off-design operation. The increase in feed water temperature will increase flue gas temperature.
This can be used for combustion air preheating otherwise the HRSG efficiency will decrease. 


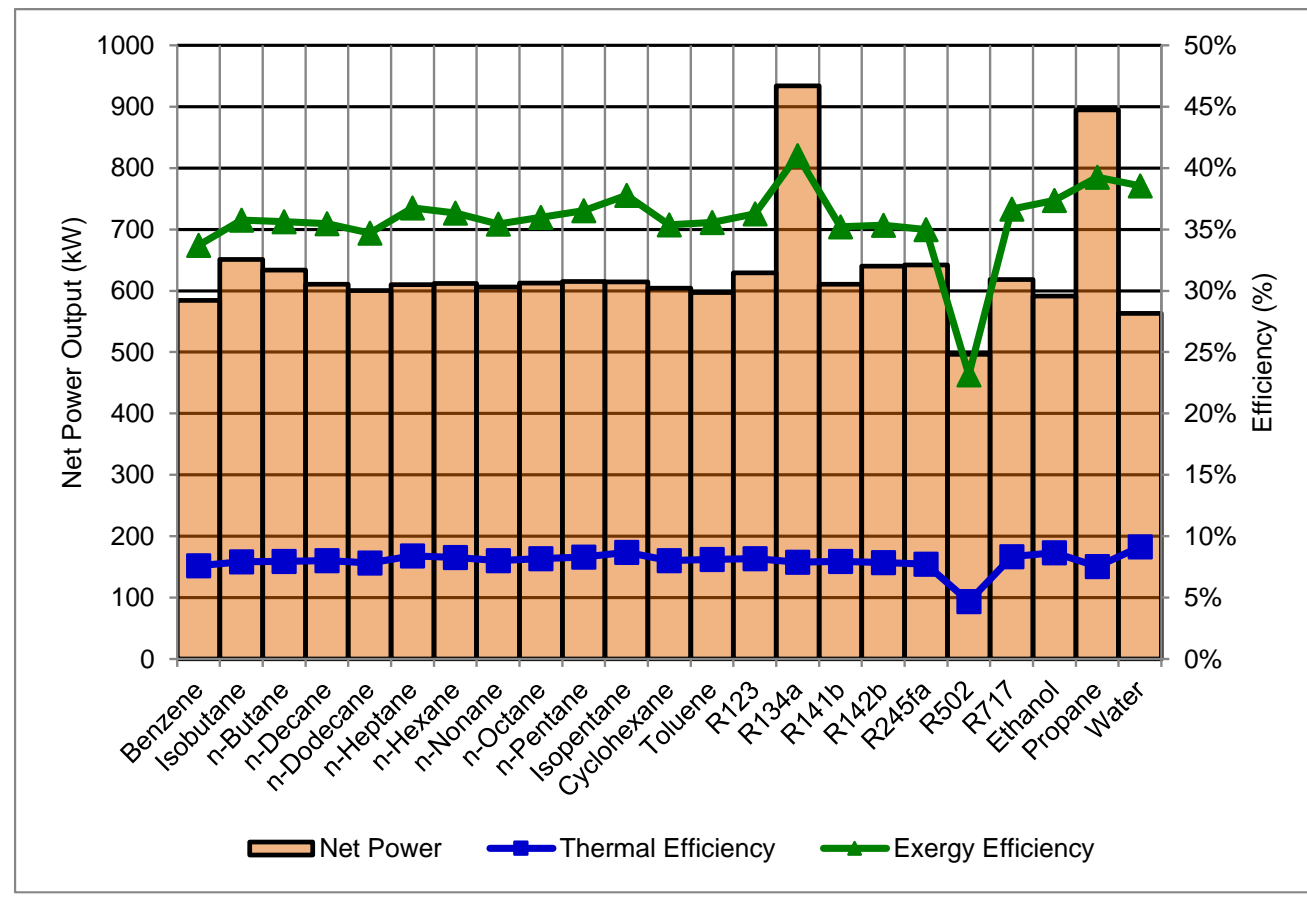

Figure 3. Net power output, thermal and exergy efficiency for working fluid candidates (Scenario 1).

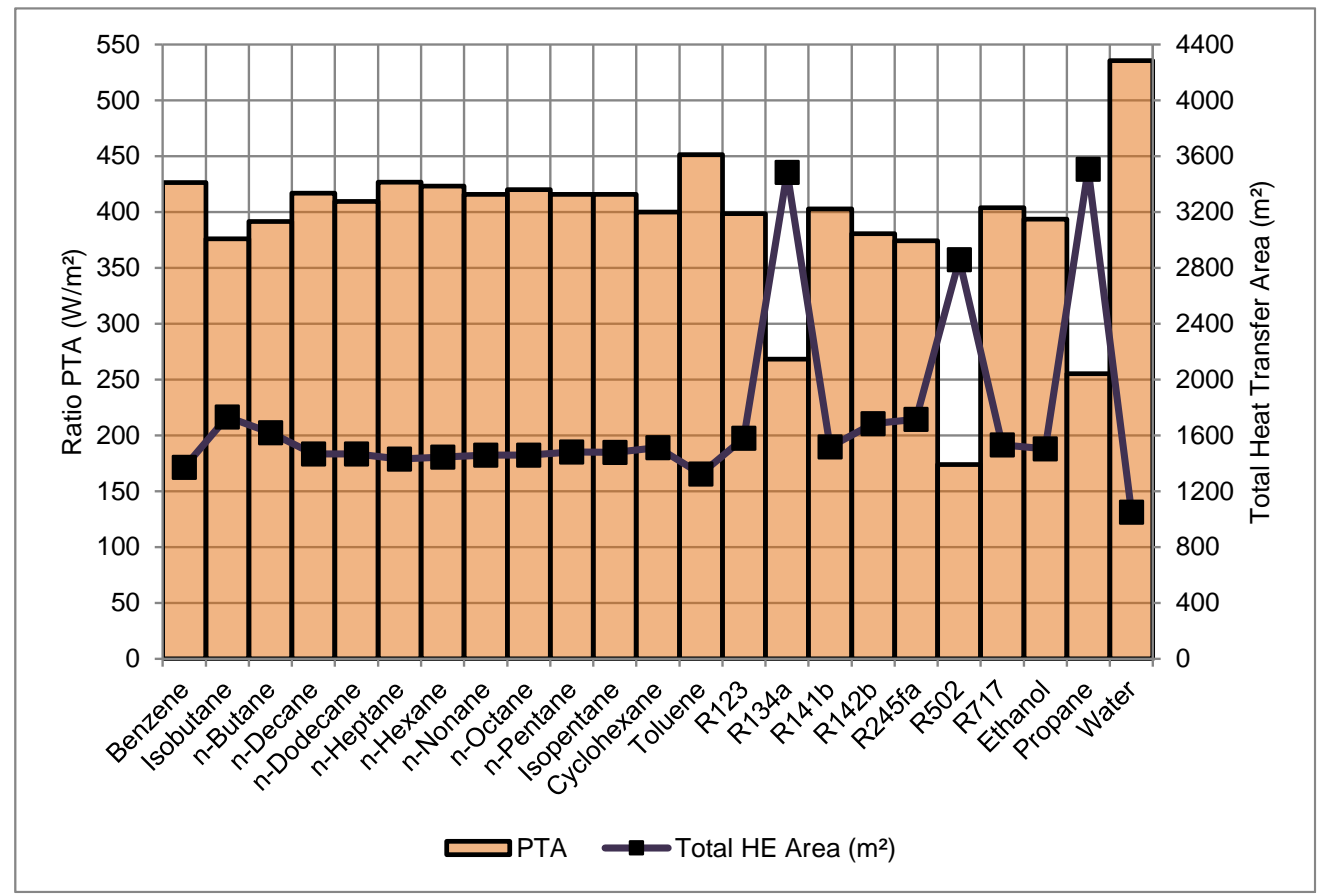

Figure 4. PTA and total heat transfer area for working-fluid candidates (Scenario 1).

Table 6. Comparison between Alternatives (Scenario1).

\begin{tabular}{lllll}
\hline Alternatives: & $\mathrm{CCP}+$ & $\mathrm{CCP}+$ & $\mathrm{CCP}+$ & CCP +Preheater + \\
& ORC & Preheater & Chiller & Chiller \\
\hline Natural Gas Consumption $(\mathrm{kg} / \mathrm{s})$ & 2.246 & 2.246 & 2.397 & 2.397 \\
Plant Global Efficiency & $53.6 \%$ & $55.0 \%$ & $53.7 \%$ & $55.5 \%$ \\
Total Heat Transfer Area $\left(\mathrm{m}^{2}\right)^{*}$ & 3,484 & 3,484 & 2,237 & 3,484 \\
Air Temperature - GT Inlet $\left({ }^{\circ} \mathrm{C}\right)$ & 25 & 25 & 8.5 & 8.5 \\
Final Light Diesel Oil Temperature $\left({ }^{\circ} \mathrm{C}\right)$ & 55.2 & 69.0 & 123.6 & 67.5 \\
Net Power Output $(\mathrm{kW})$ & 56,475 & 58,082 & 60,530 & 62,539 \\
\hline
\end{tabular}

In this scenario, although expander inlet parameters present the same behavior as the previous scenario, temperature is hardly higher than $100^{\circ} \mathrm{C}$, so a wider temperature difference is set between diesel and working fluid streams, requiring smaller heat exchangers. Besides, most working fluids enter the expander as saturated vapor, even some of those which were superheated in scenario 1 , showing that the possible gain in net power output brought by superheating is overcome by the increase in total heat exchangers area, lowering the PTA. Regarding the pressure, 
it tends to be higher, as an attempt to compensate lower expander inlet temperatures and smaller enthalpy drop.

Table 7. Selected Properties for Optimal Cycle (Scenario 2)

\begin{tabular}{lllllll}
\hline No. & Substance & $\begin{array}{l}m_{\mathrm{wf}} \\
(\mathrm{kg} / \mathrm{s})\end{array}$ & $\begin{array}{l}P_{5} \\
(\mathrm{kPa})\end{array}$ & $\begin{array}{l}T_{5} \\
\left({ }^{\circ} \mathrm{C}\right)\end{array}$ & $\begin{array}{l}\Delta T_{\text {sup }} \\
\left({ }^{\circ} \mathrm{C}\right)\end{array}$ & $\begin{array}{l}T_{11} \\
\left({ }^{\circ} \mathrm{C}\right)\end{array}$ \\
\hline 1 & Benzene & 8.9 & 168.1 & 97.5 & 0 & 109.5 \\
2 & Isobutane & 16.0 & 2040.0 & 101.5 & 0 & 98.3 \\
3 & n-Butane & 13.5 & 1536.0 & 100.3 & 0 & 100.6 \\
4 & n-Decane & 11.8 & 8.3 & 96.2 & 0 & 102.5 \\
5 & n-Dodecane & 11.7 & 1.6 & 95.4 & 0 & 102.9 \\
6 & n-Heptane & 11.9 & 98.0 & 97.2 & 0 & 102.2 \\
7 & n-Hexane & 12.1 & 228.8 & 98.1 & 0 & 102.1 \\
8 & n-Nonane & 11.7 & 18.4 & 96.3 & 0 & 102.7 \\
9 & n-Octane & 11.8 & 42.1 & 96.7 & 0 & 102.5 \\
10 & n-Pentane & 12.3 & 572.4 & 98.6 & 0 & 101.6 \\
11 & Isopentane & 13.6 & 697.5 & 98.5 & 0 & 100.1 \\
12 & Cyclohexane & 11.4 & 159.6 & 96.7 & 0 & 103.2 \\
13 & Toluene & 9.9 & 68.8 & 97.3 & 0 & 107.0 \\
14 & R123 & 27.3 & 774.4 & 99.3 & 0 & 102.0 \\
15 & R134a & 40.8 & 3823.0 & 101.6 & 3.5 & 91.9 \\
16 & R141b & 20.1 & 657.3 & 98.7 & 0 & 103.8 \\
17 & R142b & 24.8 & 2139.0 & 101.5 & 0 & 102.3 \\
18 & R245fa & 26.4 & 1254.0 & 99.5 & 0 & 99.7 \\
19 & R502 & 74.4 & 3425.0 & 78.7 & 5.2 & 80.8 \\
20 & R717 & 3.2 & 6144.0 & 99.1 & 0 & 116.5 \\
21 & Ethanol & 4.1 & 226.9 & 100.2 & 0 & 111.4 \\
22 & Propane & 22.2 & 4146.0 & 101.3 & 6.0 & 89.1 \\
23 & Water & 1.9 & 66.9 & 88.8 & 0 & 106.9 \\
\hline & & & & & &
\end{tabular}

\subsubsection{ORC Simulation and Optimization}

As shown in Figure 5, water presented the highest PTA ratio $(\sim 650 \mathrm{~W} / \mathrm{m} 2)$. It can be explained by its higher thermal conductivity and lower viscosity relatively to other candidates. Furthermore, in the Scenario of water the optimization algorithm provided no superheating (avoiding superheater area) and, as water is a wet fluid, no desuperheater is required prior condensing. However, the condensation pressure for water $\left(@ 45^{\circ} \mathrm{C}\right)$ provides negative relative pressure $(9.6 \mathrm{kPa})$. Thus, other equipment such as ejector/vacuum pumps and deaerators are required. Although its toxicity and flammability, ammonia (R717) maybe a good option since it is the second best candidate. It has a condensation pressure of $1782 \mathrm{kPa}$ (@45 oC) and presents a reasonable PTA $(\sim 600 \mathrm{~W} / \mathrm{m} 2)$, providing a simpler and economical solution.

The net power output of the optimized ORC using water is about $415 \mathrm{~kW}$ while $\mathrm{R} 717$ produces only $305 \mathrm{~kW}$. It is less than half and one third of the value $(\sim 940 \mathrm{~kW})$ found for $\mathrm{R} 134 \mathrm{a}$ when the objective function is maximum output power. The area, however, is almost five times (for water) and seven times (R717) smaller than the area required for R134a.

\subsubsection{Waste Heat Recovery Alternatives}

As result of changing the objective function from maximum power output to maximum power to area ratio, the net power output presented in Table $8(55,956 \mathrm{MW}$ to 59,321 MW) decreased in relation to the values presented in Table $6(56,475 \mathrm{MW}$ to $62,539 \mathrm{MW})$. On the other hand, the additional heat transfer areas are much smaller $\left(641 \mathrm{~m}^{2}\right.$ and $433 \mathrm{~m}^{2}$ for CCP + Chiller against $3,484 \mathrm{~m}^{2}$ and $2,237 \mathrm{~m}^{2}$ for $\mathrm{CCP}+$ Chiller for the first case), providing lower investment costs. Still, the best options are using the waste heat to preheat feed water (highest efficiency) and the water preheating and air cooling combination (highest net power).

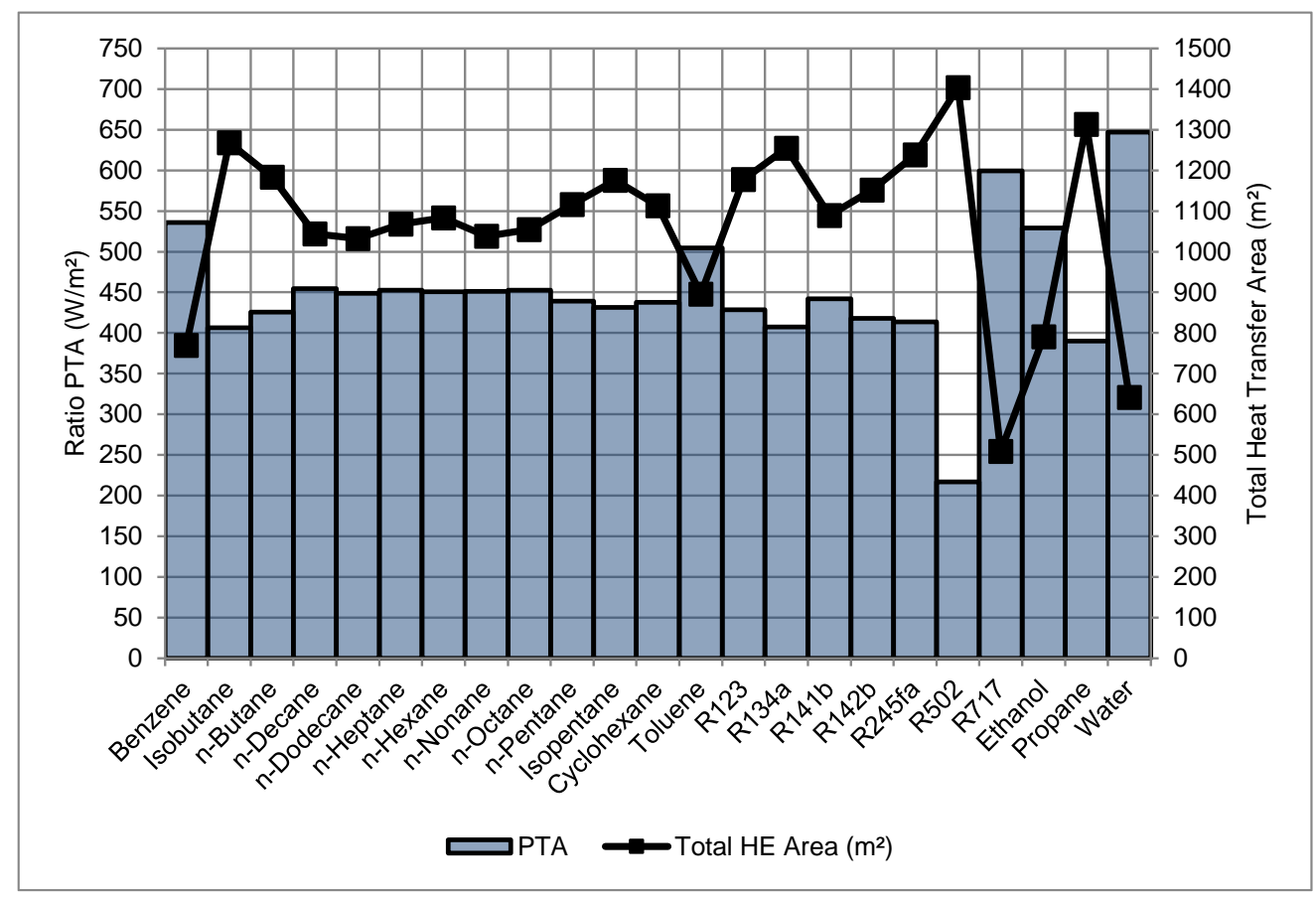

Figure 5. PTA and total heat transfer area for working-fluid candidates (Scenario 2). 


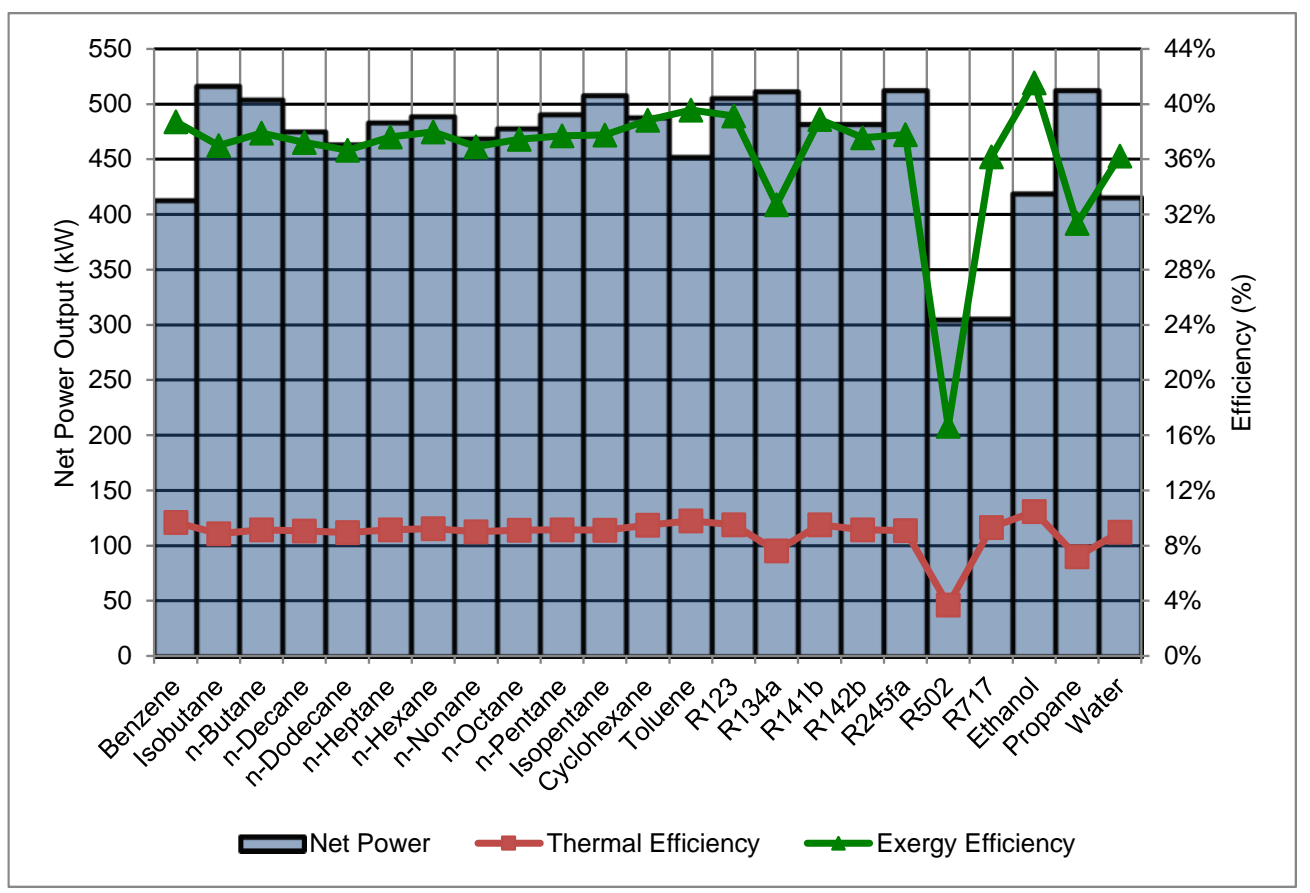

Figure 6. Net power output, thermal and exergy efficiency for working-fluid candidates (Scenario 2).

Table 8. Comparison between Alternatives (Scenario2).

\begin{tabular}{|c|c|c|c|c|}
\hline Alternatives: & $\begin{array}{l}\mathrm{CCP}+ \\
\mathrm{ORC}\end{array}$ & $\begin{array}{l}\mathrm{CCP}+ \\
\text { Preheater }\end{array}$ & $\begin{array}{l}\mathrm{CCP}+ \\
\text { Chiller }\end{array}$ & $\begin{array}{l}\text { CCP +Preheater + } \\
\text { Chiller }\end{array}$ \\
\hline Natural Gas Consumption $(\mathrm{kg} / \mathrm{s})$ & 2.246 & 2.246 & 2.317 & 2.317 \\
\hline Plant Global Efficiency (\%) & 53.0 & 54.7 & 53.2 & 54.5 \\
\hline Total Heat Transfer Area $\left(\mathrm{m}^{2}\right)^{*}$ & 641 & 641 & 433 & 641 \\
\hline Air Temperature - GT Inlet $\left({ }^{\circ} \mathrm{C}\right)$ & 25 & 25 & 17.5 & 17.5 \\
\hline Final Light Diesel Oil Temperature $\left({ }^{\circ} \mathrm{C}\right)$ & 106.9 & 79.8 & 132.9 & 95.2 \\
\hline Net Power Output $(\mathrm{kW})$ & 55.956 & 57,697 & 57,973 & 59,321 \\
\hline
\end{tabular}

*additional heat transfer area

\section{Conclusions}

Several fluids were tested to make use of the physical exergy of diesel stream in a petroleum refinery. The cycle parameters were optimized to generate maximum power output and maximum power to area ratio. The maximum power output was achieved by R134a $(\sim 940 \mathrm{~kW})$ while the maximum power to area ratio was achieved by water $(\sim 650$ $\left.\mathrm{W} / \mathrm{m}^{2}\right)$. However, water condensing pressure at environment temperatures is below atmosphere. Then, a water cycle would require the use of some auxiliary components such as vacuum pumps/steam ejectors and deaerator in order to eliminate the infiltrated air. For this reason, the second best candidate from PTA ratio optimization, R717 $\left(\sim 600 \mathrm{~W} / \mathrm{m}^{2}\right)$, maybe the primary economic option. The optimized ORCs were compared to heat integration, for HRSG feed water preheating, and hot water absorption chiller, for gas turbine inlet air cooling. The total heat transfer area calculated for the ORC was used as input for the other solutions so that the costs could be kept within the same magnitude. It was possible to conclude that the highest net power and thermal efficiency were obtained by the combined use of absorption chiller and feed water preheating when the area of the best ORC for net power $\left(3,484 \mathrm{~m}^{2}\right)$ was used. The feed water preheating and feed water preheating and absorption chiller combined solution were the best solution to increase efficiency and net power, respectively when the area for the best ORC for PTA $\left(641 \mathrm{~m}^{2}\right)$ was used. The optimized ORCs were the last option in both analyses. However, ORCs maybe the only solution among the tested options in scenarios in which a utilities plant is not present or the distances make the heat integration prohibitive.

\section{Acknowledgements:}

The authors of this paper would like to thank $\mathrm{CNPq}$ (grants 143302/2009-4 and 306505/2009-6) and Petrobras for the financial support.

\section{References}

[1] B. F. Tchanche, G. Lambrinos, A. Frangoudakis, G. Papadakis. "Low-grade heat conversion into power using organic Rankine cycles - A review of various applications". Renewable and Sustainable Energy Reviews, 15, 3963-79, 2011.

[2] T. C. Hung, T. Y. Shay, S. K. Wang. "A review of organic Rankine cycles (ORCs) for the recovery of low-grade waste heat". Energy, 22, 661-667, 1997.

[3] T. Hung. "Waste heat recovery of organic Rankine cycle using dry fluids". Energy Conversion and Management, 42, 539-53, 2001.

[4] Y. Dai, J. Wang, L. Gao. "Parametric optimization and comparative study of organic Rankine cycle (ORC) for low-grade waste heat recovery. Energy Conversion and Management, 50, 576-82, 2009. 
[5] F. Vélez, J. J. Segovia, M. C. Martín, G. Antolín, F. Chejne, A. Quijano. "Comparative study of working fluids for a Rankine cycle operating at low temperature". Fuel Process Technology, 103, 71-7, 2012.

[6] C. He, C. Liu, H. Gao, H. Xie, Y. Li, S. Wu. "The optimal evaporation temperature and working fluids for subcritical organic Rankine cycle". Energy, 38, 136-43, 2012.

[7] J. P. Roy, A. Misra. "Parametric optimization and performance analysis of a regenerative Organic Rankine Cycle using R-123 for waste heat recovery". Energy, 39, 227-35, 2012.

[8] E. H. Wang, H. G. Zhang, B. Y. Fan, M. G. Ouyang, Y. Zhao, Q. H. Mu. "Study of working fluid selection of organic Rankine cycle (ORC) for engine waste heat recovery". Energy, 36, 3406-18, 2011.

[9] S. Zhu, K. Deng, S. Qu. "Energy and exergy analyses of a bottoming Rankine cycle for engine exhaust heat recovery". Energy, 58, 448-457, 2013.

[10] H. Chen, D. Y. Goswami, E. K. Stefanakos. "A review of thermodynamic cycles and working fluids for the conversion of low-grade heat". Renewable and Sustainable Energy Reviews, 14, 3059-67, 2010.

[11] Y. R. Li, J. N. Wang, M. T. Du. "Influence of coupled pinch point temperature difference and evaporation temperature on performance of organic Rankine cycle”. Energy, 42, 503-9, 2012.

[12] G. Becquin, S. Freund. "Comparative Performance of Advanced Power Cycles for Low-Temperature Heat Sources. Proceedings ECOS 2012, 1-17, 2012.

[13] A. I. Papadopoulos, M. Stijepovic, P. Linke. "On the systematic design and selection of optimal working fluids for Organic Rankine Cycles". Applied Thermal Engineering, 30, 760-9, 2010.

[14] C. Kuo, S. Hsu, K. Chang, C. Wang. "Analysis of a 50 kW organic Rankine cycle system”. Energy, 36, 587785, 2011.
[15] J. Roy, M. Mishra, A. Misra. "Parametric optimization and performance analysis of a waste heat recovery system using Organic Rankine Cycle". Energy, 35, 5049-62, 2010.

[16] L. Pierobon, T. Nguyen, U. Larsen, F. Haglind, B. Elmegaard. "Multi-objective optimization of organic Rankine cycles for waste heat recovery: Application in an offshore platform". Energy, 58, 538 - 49, 2013.

[17] X. Li, C. Zhao, X. Hu. "Thermodynamic analysis of Organic Rankine Cycle with Ejector". Energy, 42, 342-9, 2012.

[18] S. H. Kang. "Design and experimental study of ORC (organic Rankine cycle) and radial turbine using R245fa working fluid”. Energy, 41, 514-24, 2012.

[19] H. C. Jung, S. Krumdieck, T. Vranjes. "Feasibility assessment of refinery waste heat-to-power conversion using an organic Rankine cycle". Energy Conversion and Management, 77, 396-407, 2014.

[20] S. Quoilin, M. Van Den Broek, S. Declaye, P. Dewallef, V. Lemort. "Techno-economic survey of organic rankine cycle (ORC) systems". Renewable and Sustainable Energy Reviews, 22, 168-186, 2013.

[21] J. Wang, Z. Yan, M. Wang, S. Ma, Y. Dai. "Thermodynamic analysis and optimization of an (organic Rankine cycle) ORC using low grade heat source". Energy, 49, 356-65, 2013.

[22] S. Kakaç, H. Liu, Heat Exchangers: selection, rating, and thermal design. 2nd ed. Florida: CRC Press, 2002.

[23] S. A. Klein. Engineering Equation Solver (EES), Academic version, 2012.

[24] J. A. M. Silva, O. J. Venturini, E. E. S. Lora, A. F. Pinho, J. J. C. S. Santos. "Thermodynamic information system for diagnosis and prognosis of power plant operation condition". Energy, 36, 4072-79, 2011.

[25] THERMAX Europe Ltda (February 14, 2013). Hot Water Chillers - Specification Sheet. [Online] Available: <http://www.thermax-europe.com/hotwater-spec-low-temp.aspx $>$. 